\title{
THE DESIGN, IMPLEMENTATION, AND IMPACT OF A COLLABORATIVE RESPONSIVE PROFESSIONAL DEVELOPMENT (CRPD) MODEL
}

\author{
Jinqing Liu \\ Indiana University \\ jinqliu@iu.edu \\ Gina Borgioli Yoder \\ Indiana University Purdue University Indianapolis \\ gbyoder@iupui.edu
}

\author{
Enrique Galindo \\ Indiana University \\ egalindo@indiana.edu \\ Pavneet Kaur Bharaj \\ Indiana University \\ pkbharaj@iu.edu
}

It is important to design professional development (PD) around teachers' professional thinking and needs. Researchers have explored how teachers center on and build upon students' thinking in mathematics teaching, but few studies have investigated how to identify and be responsive to teachers' ongoing needs while planning and enacting effective PD. As such, this study presents a Collaborative Responsive Professional Development (CRPD) model that arose from efforts to elicit and validate teachers' voices to design PD experiences that were relevant and meaningful to them. We share the rationale of the model design, its implementation during a two-year PD project, and its impact on teachers' instructional practice.

Keywords: Teacher Education - Inservice / Professional Development; Teacher Educators

\section{Purpose}

Avalos (2011) defined PD as "teachers learning, learning to learn, and transforming their knowledge into practice for the benefit of their students' growth" (p. 10). Putnam and Borko (1997) argued that teacher educators should engage mathematics teachers in PD in a way that is parallel to how we expect them to engage their students. Similarly, Spangler (2019) advocated that just as we are asking teachers to attend to their students' mathematical thinking, "we as teacher educators need to demonstrate the curiosity and intellectual humility that allows us to understand how and why something a teacher did or said came from a place that made sense to them" (p. 2). Additionally, researchers have noted the importance of supporting the affective side of teachers' professional growth throughout the PD process (Cross Francis, 2019, Cross Francis et al., 2019). The literature on effective PD indicates a necessary shift towards attending to teachers' needs holistically.

However, identifying and holistically responding to teachers' needs is a challenging task (Lee, 2005). Such efforts require a systematically designed PD process that situates teachers' thinking and voices as core components to all decision-making moves (Jez \& Luneta, 2018; Lee, 2005). In this study, we share what we call a Collaborative Responsive Professional Development (CRPD) model (see Figure 1), aimed at systematically centering teachers' voices and needs in an iterative process of designing, implementing, and assessing the effectiveness of our PD curriculum. Our research question was: To what extent was the implementation of the CRPD model effective for teachers' professional development?

\section{The Design of the CRPD Model}

One core aim of the CRPD model is to ensure that teachers' voices, especially regarding their professional thinking and needs, were collected in various ways, analyzed through multiple perspectives, and utilized to inform instructional decisions. We share three big ideas that undergird the CRPD Model: the research on effective PD with mathematics teachers; creating a structure for collaboration on the design of PD activities; and creating structures for systematically collecting and being responsive to teachers' voices.

In: Sacristán, A.I., Cortés-Zavala, J.C. \& Ruiz-Arias, P.M. (Eds.). (2020). Mathematics Education Across Cultures: Proceedings of the 42nd Meeting of the North American Chapter of the International Group for the Psychology of Mathematics Education, Mexico. Cinvestav / AMIUTEM / PME-NA. https:/doi.org/10.51272/pmena.42.2020 


\section{The Research on Effective PD with Mathematics Teachers}

We used three core features of effective PD as pillars upon which we built our CRPD model. The first feature is focusing on developing teachers' content and pedagogical knowledge for teaching mathematics (Darling-Hammond et al., 2017; Garet et al., 2001). This focus is responsive to strengthening elementary teachers' mathematical content knowledge and quality of mathematics instruction (Ma, 1999). The second feature is engaging teachers in active learning (DarlingHammond et al., 2017; Garet et al., 2001; Loucks-Harsley, 1996) to strengthen their pedagogical skills. Guided by the Leading for Mathematical Proficiency Framework (Bay-Williams \& McGatha, 2014), we aimed to support teachers' shifts in classroom practice. The third feature is enabling and promoting collaboration among teachers, so they feel they belong to a supportive community (Darling-Hammond et al., 2017; Galindo et al., 2014; Garet et al., 2001; Loucks-Harsley et al., 1996). Teachers built their professional learning communities in which they collaboratively reflected on and felt empowered and supported to make incremental, but powerful, shifts in their practice.

\section{Creating a Structure for Collaboration on the Design of PD Activities.}

University-school partnerships are a collaborative format for facilitating teachers' professional growth widely used in the field of mathematics education (Avalos, 2011; Bartholomew \& Sandholtz, 2009). Our PD was designed as a two-year partnership between a higher education institution and elementary mathematics teachers from eight schools (Grades K-6) in two school corporations. There are challenges in building an efficient, effective partnership (Bartholomew \& Sandholtz, 2009; Grossman, 1994; Winitzky et al., 1992). One way to strengthen the researcher-teacher (universityschool) partnership is to work collaboratively with a range of stakeholders to develop a shared vision and identifiable goals (Association of Mathematics Teacher Educators, 2017) and enable stakeholders, especially teachers, to democratically engage in decision-making via a continuous and deliberate process.

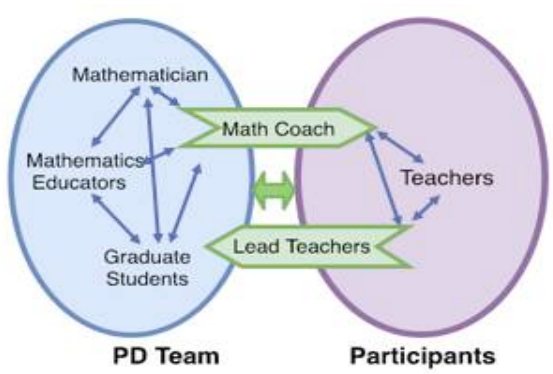

Figure 1: Forming a Structure for Centering on Teachers' Needs

The CRPD collaborative structure included two major groups: The University Team (PD Team) and In-service Mathematics Teachers Team (Participants). The Participants included classroom teachers and a Lead Teacher from each school. The PD Team included two mathematics teacher educators (MTEs), one mathematician, one mathematics coach (an experienced upper elementary and middle school teacher), and two international mathematics education graduate students (Figure 1). We should note the PD Team involved people with, at times, divergent perspectives on what they considered to be the most effective content and pedagogy curriculum or learning activities for the PD workshops.

One unique feature of this model is that the mathematics coach and lead teachers served as crucial conduits between the Participants and the PD Team. The lead teachers recognized the professional learning needs of the teachers at their schools from both practical and theoretical perspectives. Having lead teachers in the CRPD model helped create a sense of community among the participants as they felt safe sharing their concerns with someone they knew and trusted. One major role played 
by the coach was to visit teachers' classrooms daily to get an insight into the content and pedagogical needs of the teachers (Darling-Hammond et al., 2017; Gibbons \& Cobb, 2016). The coach and lead teachers were instrumental in building trusting relations between the two groups, the PD Team, and the Participants, so we could interact effectively and symbiotically.

\section{Creating Structures for Systematically Collecting Teachers' Voices}

Teachers, as adult learners, do not enter any PD session as blank slates. Instead, they bring experiences, knowledge, skills, and dispositions which impact their PD engagement, contribution, and outcomes (Ball, 1996). For the PD sessions to be meaningful and relevant, we realized the need to create structures that would provide us with continuous feedback from teachers (DarlingHammond et al., 2017; Yoon et al., 2007). Thus, we employed survey tools to identify teachers' PD goals, as well as their long-term and short-term needs.

First, to identify specific PD goals, we conducted an Initial Survey that went out to all teachers during the PD planning stage. Second, to ascertain long-term needs, each teacher completed an Annual Reflection and Personal Growth Plan form, at the beginning of 2016, 2017, and 2018, where they described what they wanted to improve in their teaching practice and shared important takeaways from the PD project. Third, to ascertain short-term needs, we designed a Workshop Feedback form to collect teachers' feedback, using both Likert-scale ratings and open-ended comments, on the quality and relevance of each learning activity in each PD session, as well as their needs and requests for future PD learning activities. In these three ways, the CRPD model design positioned teachers as active professional developers, having both a say about what professional growth they wanted and the means to attain their goals.

\section{The Implementation of the CRPD Model}

The project served 60 teachers from eight schools in two school corporations. Teachers' participation in the project included 80 hours per year, distributed among summer workshops (40 hours), two full-day workshops during the school year (one in the Fall and one in the Spring), and four after school sessions throughout the school year.

\section{Adjusting Objectives for PD Workshops According to Teachers' Voice}

Based on the Initial Survey results, we specified the main goals for this PD. After each PD session, the PD Team analyzed the Workshop Feedback Form via four stages. First, immediately after the workshop, the PD team quickly read through and sorted the surveys to identify those with fairly high Likert-scale ratings and those with lower ratings. Second, shortly after the workshop, we scanned the sorted survey responses and emailed that file to the PD team, who read through and analyzed the teachers' open-ended comments for themes. Third, email conversations took place about what themes we observed, and we brainstormed topics related to those themes that we might cover for the next PD. Finally, meetings were scheduled (in person and via Zoom) at which the PD Team worked together with the mathematics coach and the lead teachers to discuss our brainstorm ideas and to plan the agenda for the next PD based on the teachers' feedback, the coach's classroom observations, and the lead teachers' suggestions. At the end of each PD year, we used a similar process to systematically examine teachers' responses to the Annual Reflection and Personal Growth Plan form. This process systematically centered the teachers' feedback so that we were able to be responsive to it.

\section{The Impact of the CRPD Model on Teachers' Professional Growth}

Two foci of the PD were supporting teachers' understanding and implementation of the Standards for Mathematical Practice (CCSSO, 2010) and developing teachers' pedagogical content knowledge (Galindo et al., 2018). We examined the effectiveness of the CRPD model by analyzing teachers' 
statements about their major takeaways from the project and about shifts they had implemented in their instructional practice. Data sources included teachers' responses to the Reflection and Personal Growth Plan from 2017 and 2018.

From teachers' reflections about their main takeaways from the project, we found that the teachers' responses were largely centered on two process standards: 'Making sense of problems and persevere in solving them' (MPS1) and 'Constructing viable argument and critique the reasoning of others' (MPS3). Regarding MPS1, teachers acknowledged the significance of allowing students more time to explore problems to elicit multiple strategies and develop strong sense-making for the concepts. Teachers' responses signified the importance of using challenging mathematics tasks that elicit students' thinking and then assisting students in making sense of and persevering to solve the problem. For MPS3, the teachers initially expressed their inclination towards engaging students in discursive practices by promoting collaboration and communication. However, early on they were not reflecting on their role in establishing (or not) such a dialogic learning environment. Gradually, they realized that mathematical communication in their classrooms was too often teacher-dominated. One teacher wrote, "Teachers talk way too much and we all know it, we just can't stop.... I now let them share so much more and I just listen, whether it's right or wrong, I just listen. Then I ask a question, and I listen again. It is amazing the things our students can think of when we give them time to think and share." This teacher realized her role is to intentionally utilize questioning and listening to create ample opportunities and space for students to share their ideas and critique others' reasoning. These takeaways indicate the effectiveness of the PD project in promoting teachers' understanding and implementation of the mathematical practices.

In their reflections, teachers also wrote about their prior experiences as learners of mathematics and stated how experiences from this PD project changed their perceptions of mathematics and self as a mathematician. One teacher wrote, "I was not a confident math student during my school years and had a math phobia... I have learned so much from this experience. I even find myself using the strategies in my daily life. I am more confident in teaching math and helping my students. I actually love math now." Another teacher stated, "[As a learner] I memorized the algorithms we learned in school and didn't really ever question the why behind it. I feel that this training has helped deepen my understanding of math and math concepts." These statements point to the effectiveness of the PD project in positively impacting their relationship with mathematics as a subject.

\section{Discussion and Implication}

We sought to create a safe environment for the teachers to express their needs and provide honest feedback on PD learning activities, with an understanding that their voices would be heard, and the PD team would develop a responsive PD curriculum. We confirmed that cycles of emergent and responsive curriculum (Confrey \& Lachance, 2000) development are a powerful tool for centering and addressing the needs of teachers. The CRPD model democratizes PD by sharing decision-making power among the Participants and the PD Team. Teachers are given an active voice in their learning, and the math coach and lead teachers serve as strong advocates for teacher participants. Being collaborative and responsive in curriculum design requires systematic and iterative cycles of planning, implementing, and reflecting during which teachers' voices are centered, valued, and utilized.

\section{References}

Association of Mathematics Teacher Educators. (2017). Standards for Preparing Teachers of Mathematics. Retrieved from https://amte.net/standards.

Avalos, B. (2011). Teacher PD in teaching and teacher education over ten years. Teaching and Teacher Education, 27(1), 10-20. 
The design, implementation, and impact of a collaborative responsive professional development (CRPD) model

Ball, D. L. (1996). Teacher learning and the mathematics reforms: What do we think we know and what do we need to learn?, Phi Delta Kappan,7(7), 500-508.

Bartholomew, S. S., \& Sandholtz, J. H. (2009). Competing views of teaching in a school-university partnership. Teaching and teacher education, 25(1), 155-165.

Bay-Williams, J. M. \& McGatha, M. B. (2014). Mathematics coaching: Resources and tools for coaches and leaders K-12. Boston: Pearson.

CCSSO (Council of Chief State School Officers). (2010). Common core state standards. Retrieved from http://www.corestandards.org/Math/

Confrey, J., \& Lachance, A. (2000). Chapter 10: Transformative teaching experiments through conjecture-driven research design. In Lesh \& Kelly (Eds.), Handbook for design research in mathematics and science education (pp. 231-266). New York: Lawrence Erlbaum.

Cross Francis, D. (2019). Identifying the Differential Impact of an Individualized Coaching Approach. Paper presented at the annual meeting of the National Council of Teachers of Mathematics, San Diego, CA.

Cross Francis, D., Liu, J., Bharaj, P. K., \& Eker, A. (2019). Integrating Social-Emotional and Academic Development in Teachers' Approaches to Educating Students. Policy Insights from the Behavioral and Brain Sciences, 6(2), 138-146. https://doi.org/10.1177/2372732219864375

Darling-Hammond, L., Hyler, M. E., \& Gardner, M. (2017). Effective teacher PD. Palo Alto, CA: Learning Policy Institute.

Galindo, E., Lee, J., \& Borgioli Yoder, G. (2014). Building and sustaining a professional learning community: Joining in with teachers to improve mathematics teaching and learning. Journal of Mathematics Education, $7(2), 30-39$.

Galindo, E., Liu, J.,\& Bharaj, P. (2018) Supporting Shifts in Classroom Practice: Lessons from a Collaborative Professional Development, In Hodges, T.E., Roy, G. J., \& Tyminski, A. M. (Eds.). (2018). Proceedings of the 40th annual meeting of the North American Chapter of the International Group for the Psychology of Mathematics Education. (pp. 444). Greenville, SC: University of South Carolina \& Clemson University.

Garet, M. S., Porter, A. C., Desimone, L., Birman, B. F., \& Yoon, K. S. (2001). What makes PD effective? Results from a national sample of teachers. American Educational Research Journal, 38(4), 915-945.

Gibbons, L. K., \& Cobb, P. (2016). Examining content-focused coaching knowledge and practices implicated in designing coaching activities. Elementary School Journal, 117(2), 237-259.

Grossman, P. L. (1994). In pursuit of a dual agenda: Creating a middle level professional development school. Professional development schools: Schools for developing a profession, 50-73.

Hunzicker, J. L. (2010). Characteristics of effective professional development: A checklist. Retrieved from http://www.eric.ed.gov/PDFS/ED510366.pdf

Jez, R. J., \& Luneta, K. (2018). Effective Teacher Training on Inclusive Practices: Using Needs and Interests to Design Professional Development and Follow-Up Support in South Africa. Asian Journal of Inclusive Education, 6(1), 22-47.

Lee, H. J. (2005). Developing a Professional Development Program Model Based on Teachers' Needs. Professional educator, 27, 39-49.

Loucks-Horsley, S., Stiles, K., \& Hewson, P. (1996). Principles of effective PD for mathematics and science education: A synthesis of standards. National Center for Improving Science Education (NISE) Brief, 1(1), 1-6.

Ma, L. (1999). Knowing and teaching elementary mathematics: Teachers' understanding of fundamental mathematics in China and the United States. Mahwah, NJ: Erlbaum.

Putnam, R. T., \& Borko, H. (1997). Teacher learning: Implications of new views of cognition. In B.J. Biddle, T.L. Good, \& I.F. Goodson (Eds.). International Handbook of Teachers and Teaching: Springer International Handbooks of Education, Vol 3. Dordrecht: Springer.

Robinson, S. P., \& Darling-Hammond, L. (1994). Change for collaboration and collaboration for change: Transforming teaching through school-university partnerships. Professional development schools: Schools for developing a profession, 203-219.

Spangler, D.A. (2019, Feb 20, p.2) Fundamental Commitments of My Work as a Mathematics Teacher Educator. Retrieved from https://amte.net/sites/default/files/Spangler-2019-JudithJacobsLecture.pdf

Winitzky, N., Stoddart, T., \& O'Keefe, P. (1992). Great expectations: Emergent professional development schools. Journal of Teacher Education, 43(1), 3-18.

Yoon, K. S., Duncan, T., Lee, S. W.-Y., Scarloss, B., \& Shapley, K. (2007). Reviewing the evidence on how teacher PD affects student achievement (Issues \& Answers Report, REL 2007-No. 033). Washington, DC: U.S. Department of Education, Institute of Education Sciences, National Center for Education Evaluation and Regional Assistance, Regional Educational Laboratory Southwest. Retrieved from http://ies.ed.gov/ncee/edlabs 